\title{
Analysis of 2-oxothiazolidine-4-carboxylic acid by hydrophilic interaction liquid chromatography: application for ocular delivery using chitosan nanoparticles
}

\author{
Ali Athab Al-Kinanim, ${ }^{1}$ Declan P. Naughton, ${ }^{2}$ Gianpiero Calabrese, ${ }^{1}$ Anil Vangala, ${ }^{1}$ \\ James R. Smith, ${ }^{3}$ Barbara K. Pierscionek, ${ }^{1,2}$ Raid G. Alany ${ }^{1,4}$
}

${ }^{1}$ School of Pharmacy and Chemistry, Drug Discovery, Delivery and Patient Care (DDDPC) Theme, Faculty of Science, Engineering and Computing, Kingston University, London, KT1 2EE, UK

${ }^{2}$ School of Life Sciences, Faculty of Science, Engineering and Computing, Kingston University, London, KT1 2EE, $U K$

${ }^{3}$ School of Pharmacy and Biomedical Sciences, University of Portsmouth, St Michael's Building, White Swan Road, Portsmouth, PO1 2DT, UK

${ }^{4}$ School of Pharmacy, Faculty of Medical and Health Sciences, The University of Auckland, Auckland, 1142, New Zealand

\begin{abstract}
Oxidative damage due to low levels of glutathione (GSH) is one of the main causes of cataract formation. It has been reported that 2-oxothiazolidine-4-carboxylic acid (OTZ), a cysteine prodrug, can increase the cellular level of GSH. Currently, there is no analytical method to separate and quantify OTZ from aqueous humour samples for cataract research. The present study aims to develop and validate a hydrophilic interaction liquid chromatography (HILIC) method for the quantification of OTZ in simulated aqueous humour (SAH). The developed method was validated according to FDA guidelines. Accuracy, precision, selectivity, sensitivity, linearity, lower limit of quantification (LLOQ), lower limit of detection (LLOD) and stability were the parameters assessed in the method validation. The developed method was found to be accurate and precise with LLOQ and LLOD of 200 and 100 $\mathrm{ng} / \mathrm{mL}$, respectively; method selectivity was confirmed by the absence of any matrix interference with the analyte peak. The constructed calibration curve was linear in the range of $0.2-10 \mu \mathrm{g} / \mathrm{mL}$, with a regression coefficient of 0.999. In addition, the OTZ was found to be stable in SAH after three freeze/thaw cycles. Chitosan nanoparticles loaded with OTZ were formulated by the ionic gelation method. The nanoparticles were found to be uniform in
\end{abstract}


ISSN 1618-2642 (Print), 1618-2650 (Online) Published 10 Feb 2015

shape and well dispersed with average size of $153 \mathrm{~nm}$. The in vitro release of OTZ from the nanoparticles was quantified using the developed analytical method over $96 \mathrm{~h}$. Permeation of OTZ through excised bovine cornea was measured using HILIC. The lag time and the flux were $0.2 \mathrm{~h}$ and $3.05 \mu \mathrm{g} / \mathrm{cm}^{2} \mathrm{~h}$, respectively.

Keywords: HILIC . Hydrophilic interaction liquid chromatography . Nanoparticle . Drug delivery . 2Oxothiazolidine-4-carboxylic acid . Cataract

\section{Introduction}

Cataract, a major source of sight impairment, is estimated to affect more than 18 million people worldwide and is thought to be caused by protein modifications that attenuate light transmission by scattering and/or absorption, thereby detrimentally affecting the transparency of the eye lens. While glutathione (GSH) is a major antioxidant in the lens, cysteine has also been found to play a key antioxidant role in the lens nucleus. L-2-Oxothiazolidine-4carboxylic acid (OTZ) is a cysteine prodrug that can increase the cellular level of GSH [1]. OTZ, a secondary precursor for GSH, is enzymatically metabolised to cysteine by the action of 5-oxoprolinase and, thus, increases the overall level of GSH [1]. Therefore, a simple topical solution of OTZ might enhance the intracellular level of GSH. Nevertheless, after instillation of a conventional eye drop, extensive precorneal loss caused by nasolacrimal drainage and high tear fluid turnover leads to a relatively short precorneal contact time, hence reduced ocular bioavailability [2].

In the last few decades, nano-systems have attracted attention in drug delivery research. Chitosan is used in the preparation of nanoparticles due to its appealing properties. The positive surface charge of chitosan renders it attractive for ocular drug delivery, as chitosan nanoparticles are likely to interact with the negatively charged surface of the eye. It is likely to increase the residence time of the drug and prolong precorneal retention time, thereby enhancing ocular drug bioavailability [2].

The present study reports on the development and validation of a new highly sensitive HILIC method for separation and quantification of the released/permeated OTZ in simulated aqueous humour (SAH). The method was used to quantify OTZ release from chitosan nanoparticles and permeation through excised bovine cornea. 
ISSN 1618-2642 (Print), 1618-2650 (Online) Published 10 Feb 2015

\section{Experimental}

\section{Materials}

OTZ was obtained from MP Biomedicals (CA, USA). Ammonium acetate, HPLC grade acetonitrile, sodium hydroxide, sodium sulphate, calcium chloride and glucose were purchased from Fisher Scientific (Loughborough, UK). All other reagents were purchased from Sigma-Aldrich (Dorset, UK). Analytical grade chemicals were used as received unless mentioned otherwise.

\section{Stock solutions and standards}

Simulated aqueous humour (SAH) was prepared following an existing procedure [3] with some modification. A master stock solution of OTZ was freshly prepared by dissolving OTZ $(10 \mathrm{mg})$ in SAH $(10 \mathrm{~mL})$ in a volumetric flask. Different concentrations $(0.2,0.5,1,2,3,5$ and $10 \mu \mathrm{g} / \mathrm{mL})$ were prepared from the stock solution; these concentrations were used to construct the calibration curve for validation. In addition, quality control solutions were prepared by diluting the master stock solution with SAH. Samples were stored at $4{ }^{\circ} \mathrm{C}$ until further use.

\section{Chromatographic conditions}

The method was developed and validated using a Shimadzu LC-2010HT (Kyoto, Japan) HILIC system which is comprised of a serial dual plunger, micro volume pump, automatic degasser, thermostatic autosampler and a column oven. The system uses a deuterium lamp UV detector set at $265 \mathrm{~nm}$. Separation and quantification were achieved using a HILIC column (Kinetex $100 \times 4.6 \mathrm{~mm}$ ) with a pre-column ultra-cartridge security guard (Phenomenex, California, USA); the column was maintained at $30{ }^{\circ} \mathrm{C}$. The mobile phase consisted of acetonitrile (phase A) and $10 \mathrm{mM}$ ammonium acetate (phase B).Optimum separation was obtained when the mobile phases were run in a linear gradient mode starting with $95 \%$ acetonitrile and ending with 95\%ammoniumacetate (at a flow rate of $1.5 \mathrm{~mL} / \mathrm{min}$ ) with a run time of $15 \mathrm{~min}$, followed by additional $2 \mathrm{~min}$ for column conditioning.

\section{Method validation}

The developed method was validated according to FDA guidelines. Accuracy, precision, linearity, lower limit of detection (LLOD), lower limit of quantification (LLOQ), selectivity, sensitivity, and stability were the fundamental parameters for validation of the developed method. The calibration curve of area under the curve versus concentration was constructed from the seven concentrations that were prepared from the stock solution (as described above). Three different quality control samples - quality control low (QCL), quality control medium 
ISSN 1618-2642 (Print), 1618-2650 (Online) Published 10 Feb 2015

(QCM) and quality control high $(\mathrm{QCH})$ - were prepared to determine the accuracy and intra- and inter-day precisions; these samples were equally distributed over the linear range of the calibration curve. Six replicas of each quality control concentration were measured. The accuracy of the method was calculated by comparing the measured mean of the six replicas of each concentration with the respective nominal values. The calculated mean value for four of the six quality control sample replicas should not deviate by more than $\pm 15 \%$, with the exception of the LLOQ for which the mean value should be within $\pm 20 \%$. For the intra-day precision experiment, six replicas of the same concentration were measured on the same day, while the inter-day precision was determined by measuring six replicas of the same concentration on three consecutive days. The coefficient of variation (CV) was used to give an indication of the precision of the developed method. A CV value of $\pm 15 \%$ was considered acceptable for all quality control samples apart from LLOQ where CV value of \pm 20 were deemed acceptable. A blank sample was introduced between the analyses; the absence of any interference from the matrix peaks with the analyte peaks was deemed an acceptable indication of method selectivity. Finally, linear regression analysis was used to test for method linearity. To assess the stability of the method, a SAH spiked with OTZ was stored at -20 ${ }^{\circ} \mathrm{C}$ and three freeze/thaw cycles were performed.

\section{OTZ-loaded chitosan nanoparticles}

Chitosan nanoparticles were formulated by ionic gelation [4]. Briefly, OTZ $(0.6 \mathrm{mg} / \mathrm{mL})$ was added to chitosan solution $(5 \mathrm{~mL} ; 1.75 \mathrm{mg} / \mathrm{mL})$; the solution was stirred for $1 \mathrm{~h}$. TPP solution $(2 \mathrm{~mL} ; 1.5 \mathrm{mg} / \mathrm{mL})$ was added drop wise to this solution. This resulted in a particulate dispersion which was placed in an ice bath and sonicated for 30 s. This dispersion was centrifuged at 40,000g for $30 \mathrm{~min}$. The nanoparticles obtained were re-dispersed in water. Particle size and $\zeta$-potential of the prepared particles were measured at $20{ }^{\circ} \mathrm{C}$ using a Malvern Mastersizer 3000HSA, UK. Scanning electron microscopy (SEM) (Zeiss EVO50, Germany) and atomic force microscopy (AFM) (MultiMode/NanoScope IV scanning probe microscope, Santa Barbara, Bruker, USA) were used to characterise the morphology of the prepared particles. AFM experiments were performed, as described elsewhere [5]. The images were then processed and height profiles extracted using NanoScope Analysis software (V 1.4, Bruker, CA, USA). SEMsamples were prepared as follows: One drop of the nanoparticle suspension was placed on a slide cover and left to dry overnight. The slide cover was then attached to an aluminium stud using double-sided adhesive conductive carbon tape. The sample was coated with a layer of gold/ palladium using sputter coating and then analysed under high vacuum at a voltage of $20 \mathrm{kV}$.

\section{In vitro release study of $\mathrm{OTZ}$}

A dialysis membrane (10,000 Da MWCO) was soaked overnight in SAH. A Franz cell diffusion apparatus (FDC-6, Logan Instrument Corp., Somerset, NJ, USA) was used. The receptor compartment (orifice diameter $15 \mathrm{~mm}$ ) was 
ISSN 1618-2642 (Print), 1618-2650 (Online) Published 10 Feb 2015

filled with SAH (12 mL), and a dispersion of OTZ-loaded chitosan nanoparticles $(2 \mathrm{~mL})$ was placed in the donor compartment. The two compartments were separated by the dialysis membrane. The temperature of the cell was maintained at $35 \pm 0.5{ }^{\circ} \mathrm{C}$. At hourly intervals, an aliquot $(400 \mu \mathrm{L})$ was withdrawn from the receptor compartment for analysis; this volume was replaced with fresh SAH. The OTZ released from the nanoparticles was quantified by the developed HILIC method.

\section{Ex vivo corneal permeation of $O T Z$}

Corneal permeation of OTZ was investigated using the Franz cell diffusion apparatus. The two compartments were separated by a freshly excised bovine cornea (endothelium facing the receptor compartment). The temperature of the cell was maintained at $35 \pm 0.5^{\circ} \mathrm{C}$. A sample $(400 \mu \mathrm{L})$ was withdrawn from the receptor compartment at set time intervals (every $1 \mathrm{~h}$ ) and replaced with fresh SAH. The samples were analysed for permeated OTZ by HILIC. The apparent permeability coefficient $\left(\mathrm{P}_{\text {app }}\right)$ was calculated from the amount of OTZ permeated versus time plot using:

$$
\mathrm{P}_{\mathrm{app}}=\frac{\Delta Q}{\Delta t(3600) A C_{0}}
$$

where $\Delta \mathrm{Q} / \Delta \mathrm{t}$ is themass $(\mu \mathrm{g})$ permeated at different time $(\mathrm{h})$ points $(\mu \mathrm{g} / \mathrm{h})$ of OTZ through the excised bovine corneas, $\mathrm{C} 0$ is the initial concentration $(\mu \mathrm{g} / \mathrm{mL})$ of OTZ and A is the area of the Franz cell orifice $\left(\mathrm{cm}^{2}\right)$. Lag time was obtained by dividing the value of the intercept over the slope; the latter represents the value of the $\mathrm{P}_{\text {app }}$ of OTZ.

\section{Results and discussion}

\section{Method development and validation}

Separation and quantification of OTZ, a small hydrophilic molecule, by HPLC have been reported previously [6]. The reported method had some shortcomings; separation of OTZ by conventional HPLC is challenging because of the highly hydrophilic nature of the OTZ rendering it too polar for conventional HPLC column separation [7]. HILIC is an alternative HPLCmode for separation of polar compounds using the same mobile phases used in normal phase liquid chromatography; it combines the appropriate features of both normal and reverse phase liquid chromatography [7]. HILIC utilises the same stationary phase of normal phase liquid chromatography while the mobile phase is similar to that used in reverse phase liquid chromatography. Different combinations of the mobiles phases were used during the method development; a small amount of water with a water miscible organic solvent is considered to be a good combination of mobile phases. The HILIC column relies on the presence of a bilayer of the two mobile phases [7]; therefore, a limit of $95 \%$ of either mobile phase was maintained. In contrast to reversephase liquid chromatography, the gradient run for a HILIC column begins with an excess of organic phase over the 
ISSN 1618-2642 (Print), 1618-2650 (Online) Published 10 Feb 2015

aqueous phase to improve column retention [8]. Therefore, a gradient mode was adopted starting with $75 \%$ of acetonitrile and ending with $75 \%$ of ammonium acetate; this resulted in good separation but with a long retention time. By increasing the acetonitrile level to $95 \%$ and ending with $95 \%$ of the aqueous phase, the optimum separation with the shortest retention time was achieved. The running time for the method was $15 \mathrm{~min}$, followed by $2 \mathrm{~min}$ column reconditioning with $95 \%$ acetonitrile.

The developed method showed good linearity between 0.2 and $10 \mu \mathrm{g} / \mathrm{mL}$ (quantification range) with a regression coefficient of 0.999 . The LLOD for OTZ in SAH was $100 \mathrm{ng} / \mathrm{mL}$ with signal $/$ noise $(\mathrm{S} / \mathrm{N})$ ratio of 6.5 , while the LLOQ was found to be $200 \mathrm{ng} / \mathrm{mL}$ with 14.42 as $\mathrm{S} / \mathrm{N}$ ratio. The accuracy and inter- and intra-day precision were found to be within the limits set by the FDA guidelines (Table 1). No interference between the analyte and blank (SAH) peaks was identified which confirmed the method selectivity (Fig. 1a); the peak was well defined with good separation from any endogenous matrix peaks (Fig. 1b). The stability of the OTZ in SAH was evaluated by running three freeze/thaw cycles which revealed no change in the OTZ concentration in SAH.

\section{OTZ-loaded chitosan nanoparticles}

Size and $\zeta$-potential of the formulated chitosan nanoparticles are amongst the most important parameters that control the bioactivity and biocompatibility of the prepared particles [4]; smaller particles are likely to have a higher permeation than larger ones, and positively charged particles are likely to have longer ocular retention time due the presence of the negatively charged mucin layer [2]. The particle size and $\zeta$-potential of the prepared chitosan nanoparticles were measured and found to be $153 \pm 3 \mathrm{~nm}$ and $26 \pm 0.5 \mathrm{mV}$, respectively (Fig. 2a, b). Our particle sizes were smaller compared to those of Calvo et al. [4], and the surface charge of the prepared particles was positive due the presence of the protonated amine groups on the chitosan backbone. The polydispersity index was 0.08 which indicates monodisperse systems.

Table 1 Summary of intra-, inter-day and freeze/thaw cycles precision and accuracy for the detection of OTZ in SAH

\begin{tabular}{|c|c|c|c|c|c|c|c|c|c|}
\hline \multirow{2}{*}{$\begin{array}{l}\text { Spiked } \\
\text { concen- } \\
\text { tration } \\
\text { of OTZ in } \\
\text { SAH } \\
(\mu \mathrm{g} / \mathrm{mL})\end{array}$} & \multicolumn{3}{|l|}{ Intra-day $(n=6)$} & \multicolumn{3}{|c|}{ Inter-day $(n=6+6+6)$} & \multicolumn{3}{|c|}{ Freeze/thaw cycles $(n=6+6+6)$} \\
\hline & $\begin{array}{l}\text { Measured } \\
\text { concentration } \\
(\mu \mathrm{g} / \mathrm{mL})\end{array}$ & $\begin{array}{l}\text { Precision } \\
(\%)\end{array}$ & $\begin{array}{l}\text { Accuracy } \\
(\%)\end{array}$ & $\begin{array}{l}\text { Measured } \\
\text { concentration } \\
(\mu \mathrm{g} / \mathrm{mL})\end{array}$ & $\begin{array}{l}\text { Precision } \\
(\%)\end{array}$ & $\begin{array}{l}\text { Accuracy } \\
(\%)\end{array}$ & $\begin{array}{l}\text { Measured } \\
\text { concentration } \\
(\mu \mathrm{g} / \mathrm{mL})\end{array}$ & $\begin{array}{l}\text { Precision } \\
(\%)\end{array}$ & $\begin{array}{l}\text { Accuracy } \\
(\%)\end{array}$ \\
\hline $\begin{array}{l}0.2 \\
\text { (LLOQ) }\end{array}$ & $0.224 \pm 0.007$ & 2.934 & 112.000 & $0.215 \pm 0.013$ & 6.006 & 107.686 & $0.225 \pm 0.005$ & 2.240 & 103.111 \\
\hline 0.3 (QCL) & $0.314 \pm 0.003$ & 1.073 & 104.700 & $0.310 \pm 0.017$ & 5.503 & 103.296 & $0.309 \pm 0.006$ & 1.859 & 103.111 \\
\hline $2.5(\mathrm{QCM})$ & $2.451 \pm 0.010$ & 0.389 & 98.000 & $2.474 \pm 0.015$ & 0.607 & 98.960 & $2.469 \pm 0.044$ & 1.784 & 98.760 \\
\hline $7.5(\mathrm{QCH})$ & $7.502 \pm 0.030$ & 0.394 & 100.031 & $7.526 \pm 0.023$ & 0.300 & 100.351 & $7.558 \pm 0.039$ & 0.520 & 100.778 \\
\hline
\end{tabular}



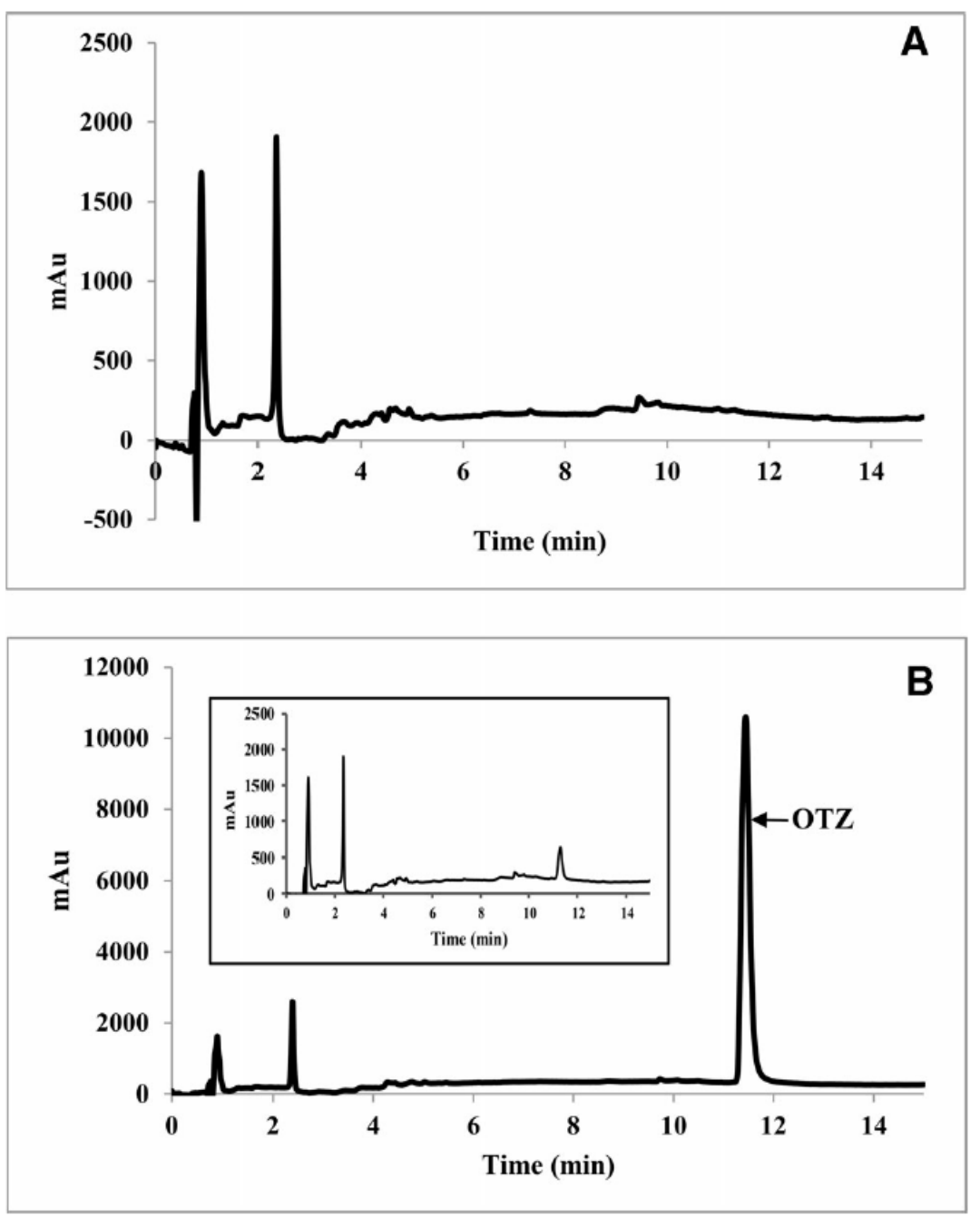

Fig. 1 A HILIC chromatogram of SAH only. B HILIC chromatogram of OTZ in SAH

The morphology of chitosan nanoparticles was elucidated using SEM (Fig. 2c) and AFM (Fig. 2d). The particles appeared to be spherical, uniform in shape, with limited aggregation. AFM topography images were obtained, in air, from four replicates, each prepared from aqueous solutions. The particle diameters determined using AFM were found to be in agreement with diameters obtained from particle size analyses and SEM images and not influenced by possible tip broadening artefacts [9].

\section{In vitro release of $O T Z$}

The release profile of OTZ from chitosan nanoparticles indicated an initial burst release of OTZ over the first $6 \mathrm{~h}$ which likely is caused by the rapid desorption of the OTZ molecules that are adsorbed onto the surface of the chitosan nanoparticles. This was followed by a sustained release phase where the rate of OTZ release declined 
ISSN 1618-2642 (Print), 1618-2650 (Online) Published 10 Feb 2015

notably most likely because of the slow diffusion of OTZ from the core of the chitosan nanoparticles [4]. The percentage of OTZ released over the period of the experiment was $14.7 \%$ which is in agreement with previous results [4].

These findings suggest that a significant amount of OTZ has been retained in the nanoparticle system most likely because of the strong electrostatic interaction between the positively charged amine groups of the chitosan amine groups and the negatively charged OTZ. Nevertheless, the amount of released OTZ is still within the therapeutic window and, as such, would be suitable for the intended purpose [10].

\section{Ex vivo corneal permeation of $O T Z$}

The OTZ permeation through excised bovine cornea profile is linear, indicating that the corneal epithelium controls the permeation of OTZ. The lag time and the corneal flux of OTZ were calculated and found to be $0.2 \mathrm{~h}$ and 3.05 $\mu \mathrm{g} / \mathrm{cm}^{2} \mathrm{H}$, respectively, while the $\mathrm{P}_{\text {app }}$ was found to be $3.2 \times 10^{-7} \mathrm{~cm} \mathrm{~s}^{-1}$.
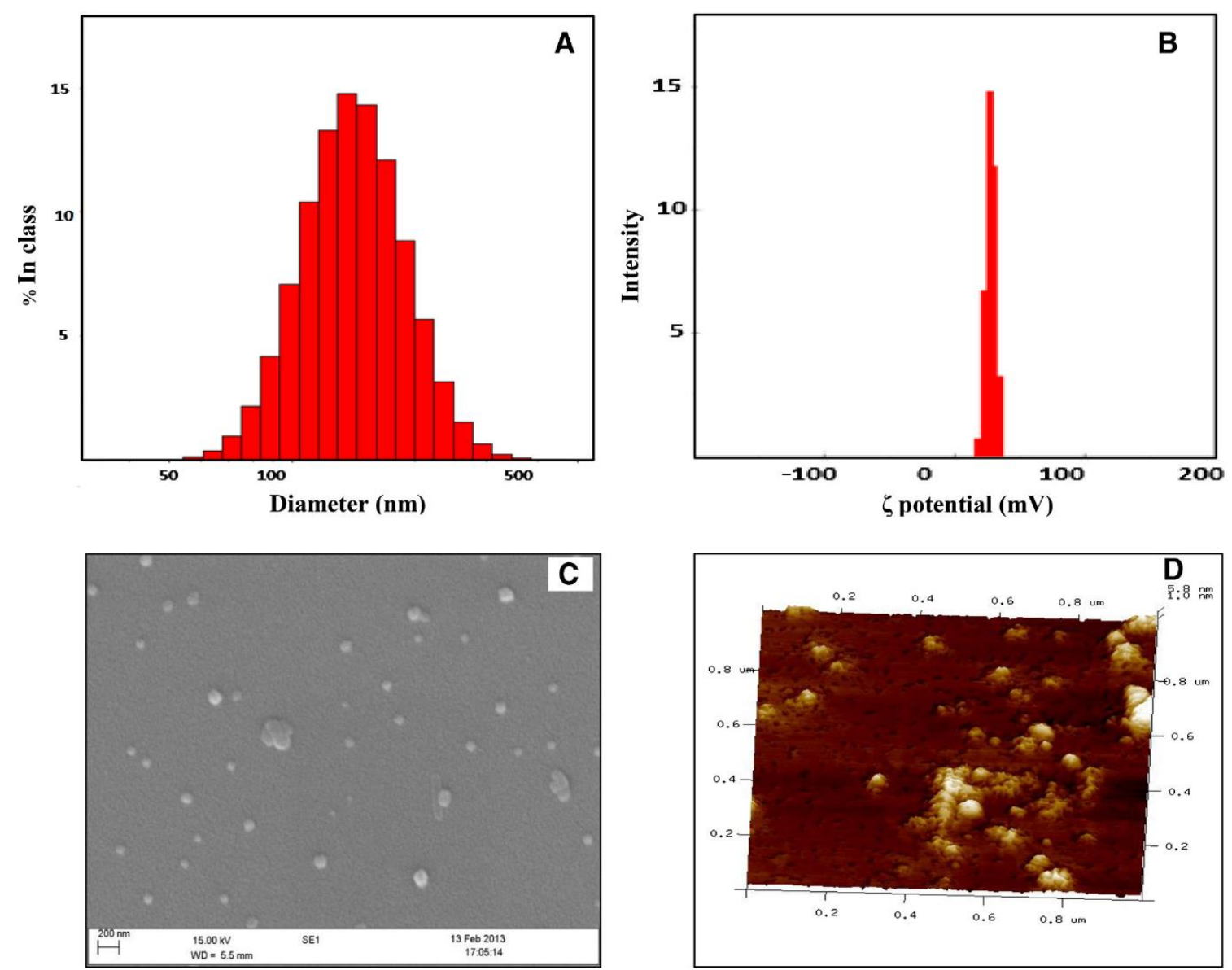

Fig. 2 Chitosan nanoparticle's size and shape characteristics. A Particle size distribution, $\mathbf{B} \zeta$ potential. Results are expressed as a mean value $\pm \mathrm{SD}(\mathrm{n}=3), \mathbf{C}$ SEM micrograph and $\mathbf{D}$ AFM micrograph 


\section{Conclusion}

A new method for separation and quantification of OTZ in SAH has been developed and validated according to FDA guidelines. This method highlights the advantage of employing an HILIC column to overcome the hydrophilicity challenge characteristic of OTZ. The method was found to be accurate, precise, selective and highly sensitive with a LLOD of $100 \mathrm{ng} / \mathrm{mL}$ and a LLOQ of $200 \mathrm{ng} / \mathrm{mL}$. OTZ-loaded chitosan nanoparticles were formulated by ionic gelation and investigated for particle size and morphology. The amount of OTZ released and permeated across excised bovine eye cornea was quantified using the developed method.

\section{Acknowledgements}

The authors would like to thank Kingston University London, Faculty of Science, Engineering and Computing for providing Mr. Ali Athab Al-Kinani with a Ph.D. scholarship. Also, we would like to thank Dr. Julian Swinden, Richard Giddens and Wendy Brosnan for their technical support. Sodium hyaluronate (from bovine vitreous humour) was kindly gifted from Sigma-Aldrich (Dorset, UK).

\section{References}

1. Vita JA, Frei B, Holbrook M, Gokce N, Leaf C, Keaney JF Jr (1998) L-2-Oxothiazolidine-4-carboxylic acid reverses endothelial dysfunction in patients with coronary artery disease. J Clin Invest 101(6): 1408-1414

2. Al-Kinani AA, CalabreseG,Vangala A, Naughton D, Alany RG (2012) In: Souto EB (ed) Patenting nanomedicines, vol 1. Springer, Berlin

3. Chirila TV, Morrison DA, Gridneva Z, Meyrick D, Hicks CR, Webb JM (2005) Effect of multipurpose solutions for contact lens care on the in vitro drug-induced spoliation of poly(2-hydroxyethyl methacrylate) in simulated aqueous humour. Cont Lens Anterior Eye 28(1):21-28

4. Calvo P, Remuñán-López C, Vila-Jato JL, Alonso MJ (1997) Novel hydrophilic chitosan-polyethylene oxide nanoparticles as protein carriers. J Appl Polym Sci 63(1):125-132

5. Theodoropoulos D, Rova A, Smith JR, Barbu E, Calabrese G, Vizirianakis IS, Tsibouklis J, Fatouros DG (2013) Towards boron neutron capture therapy: the formulation and preliminary in vitro

evaluation of liposomal vehicles for the therapeutic delivery of the dequalinium salt of bis-nido-carborane. Bioorg Med Chem Lett 23(22):6161-6166

6. Gwilt P, Radick L, Li X,Whalen J, Leaf C (1998) Pharmacokinetics of 2-oxothiazolidine-4-carboxylate, a cysteine prodrug, and cysteine. J Clin Pharmacol 38:945-950 
Analytical and Bioanalytical Chemistry 407 (8) (2015) 2645-2659. 10.1007/s00216-015-8494-8

ISSN 1618-2642 (Print), 1618-2650 (Online) Published 10 Feb 2015

7. Buszewski B, Noga S (2012) Hydrophilic interaction liquid chromatography (HILIC)-a powerful separation technique. Anal Bioanal Chem 402(1):231-247

8. Cubbon S, Bradbury T, Wilson J, Thomas-Oates J (2007) Hydrophilic interaction chromatography for mass spectrometric metabonomic studies of urine. Anal Chem 79(23):8911-8918

9. Eaton P,West P (2010) Atomic force microscopy. Oxford University Press, Oxford

10. Keawchaoon L, Yoksan R (2011) Preparation, characterization and in vitro release study of carvacrol-loaded chitosan nanoparticles. Colloids Surf B: Biointerfaces 84(1):163-171 